\title{
Larger Axis of Placenta
}

National Cancer Institute

\section{Source}

National Cancer Institute. Larger Axis of Placenta. NCI Thesaurus. Code C117340.

The length, in $\mathrm{cm}$, of the longest axis of the chorionic disc. 